\title{
Slug Test in a Large Dip Angle Fracture Zone: Model and Field Experiment
}

\author{
Ying Liu ${ }^{1}$ and Chia-Shyun Chen ${ }^{2, *}$ \\ ${ }^{I}$ School of Water Resources and Environment, China University of Geosciences, Beijing, P.R. China \\ ${ }^{2}$ Graduate Institute of Applied Geology, National Central University, Jhongli, Taiwan, R.O.C.
}

Received 5 February 2015, revised 28 March 2015, accepted 9 April 2015

\begin{abstract}
A single-porosity model is developed to deal with a fracture zone slug test in a large dip angle by assuming the fracture zone causes a downward regional flow. For the oscillatory response, a larger dip angle causes larger amplitude while introduces little impact on period. The effective water length, an important parameter necessary for analyzing the oscillatory response, is proven to be independent of the dip angle and can be evaluated using the available horizontal formation methods. The dip angle effect is more pronounced for a larger storage coefficient. An empirical relationship is developed to evaluate the limiting dip angle, below which the dip angle effect is negligible. Field data analysis of a slug test in a $47^{\circ}$ dip angle fracture zone indicates that neglecting the dip angle can result in a 27\% transmissivity over estimation and a 53\% storage coefficient under estimation.
\end{abstract}

Key words: Slug test model, Dip angle, Fracture zone, Field data analysis

Citation: Liu, Y. and C. S. Chen, 2015: Slug test in a large dip angle fracture zone: Model and field experiment. Terr. Atmos. Ocean. Sci., 26, 587-598, doi: 10.3319/TAO .2015.04.09.01(Hy)

\section{INTRODUTION}

The slug test is a relatively simple field method for estimating pertinent hydrogeologic parameters. Slug testing has been widely used in either granular aquifers or fractured formations. There are many studies for the slug test under various hydrogeological test conditions. It is well recognized (e.g., Van der Kamp 1976; Kipp 1985; Butler 1998; Zurbuchen et al. 2002; and so on) that the slug test response is oscillatory under a relatively high permeable condition while non-oscillatory under a relatively low permeable condition. Most of the works prior to 1998 can be found in Butler (1998), and those after 1998 include; e.g., McElwee and Zenner (1998); Zlotnik and McGuire (1998); Zurbuchen et al. (2002); Butler et al. (2003); Butler and Zhan (2004); Ostendorf et al. (2005); Chen (2006); Ross and McElwee (2007); Alexander et al. (2011); Rozos et al. (2015); and so on. Cooper et al. (1967) conducted one pioneering work in slug testing. There are double-porosity models, specifically for fractured formations, that take into account the interactive flow between the fracture and adjacent porous matrices based on various flow mechanism assumptions (e.g., Barker and Black 1983; Dougherty and Babu 1984; Mateen

\footnotetext{
* Corresponding author

E-mail: chenchia@cc.ncu.edu.tw
}

and Ramey 1984; Moench 1984; Black 1985; Sageev and Ramey 1986; Grader and Ramey 1988; Barker et al. 2000), and the fractal geometry models of a fractional flow dimensionality between 1 and 3 (e.g., Barker 1988; Novakowski and Bickerton 1997; Audouin and Bodin 2008). All of these models assume that the aquifer or formation being investigated is horizontal with little or no dip angle effect, in which the flow field caused by the slug test is assumed to be radially symmetric with respect to the test well.

However, field investigations conducted in a Cenozoic folded sandstone formation revealed that the dip angle of a fracture zone is as large as $47^{\circ}$. For a large dip angle, a uniform regional flow prevails through the sloping fracture zone and its presence will cause the flow field due to the slug test to be asymmetrical with respect to the test well. This asymmetric flow is similar to that of a regional flow superimposed onto a radial flow; e.g., see McWhorter and Sunada (1981, Figs. 4 - 12) for the steady-state condition. As shown by these figures, the asymmertic flow is characteristic of a "groundwater divide" that consists of all the points of a zero hydraulic gradient because of the balance of the radial flow caused by the pumping well and the uniform regional flow. This divide extends to infinity up gradient of the pumping well while terminates at a stagnant point somewhere down gradient of the pumping well. All 
the groundwater within the divide can be withdrawn by the pumping well. All the groundwater outside the divide; however, bypasses the pumping well. Clearly, all of the currently available slug test models are not suitable for such a flow field, and thus how the large dip angle will influence the slug test response warrants study. It is important to have appropriate data analysis methods for both the oscillatory and non-oscillatory test responses with the dip angle effect, and to know when the dip angle effect can be neglected (more specifically, the limiting dip angle smaller than which the dip angle effect can be neglected.) Therefore, the purpose of this paper is to develop a slug test model that takes into account the dip angle effects and investigates the dip angle influence on the oscillatory and non-oscillatory slug test response. The test response solution and analysis in nearby observation wells will be presented elsewhere.

\section{MATHEMATICAL MODEL AND SOLUTIONS}

\subsection{Model Development}

The problem of interest is schematically illustrated in Fig. 1a, where a double-packer slug test is conducted in a sloping fracture zone with a dip angle $\alpha$ and aperture $b \cos \alpha$, $b$ being the vertical uniform thickness of the fracture zone. Groundwater in the fracture zone can enter or leave the borehole only through the test section between the packers. The borehole radius is $r_{w}$. The test response $H(t)$ is measured using a pressure transducer submerged in the riser pipe of radius $r_{c}$. The model is developed based on the single-porosity approach, considering that a double-porosity characteristic is usually evident only at large times where the test response is too small to be practically useful (Butler 1998). As a result, the fracture zone is assumed to be a homogeneous and isotropic continuous porous medium under the confined condition, where Darcy's law is applicable. It is understood that the flow in close vicinity of the test well can be larger than non-Darcian flow (e.g., Wu 2002). This possible condition is not taken into account in the current model.

Owing to the dip angle, the elevation head $Z(x, y)$ of the fracture zone varies as $\partial Z / \partial x=\tan \alpha$, where $x=l \cos \alpha$ is the horizontal projection of $l$. Accordingly the piezometric head can be expressed as

$h(x, y, t)=P(x, y, t)+x \tan \alpha$

where $P(x, y, t)$ represents the pressure head. It is assumed that the dipping angle induces a downward regional flow of uniform hydraulic gradient $\partial Z / \partial x=\tan \alpha$ in the fracture zone. The problem associated with an upward regional flow in the fracture zone will be presented elsewhere.

Note that the current model is unavailable for a vertical fracture zone because $\alpha=\pi / 2$ leads to an infinity hydraulic gradient for the downward regional flow [i.e., $\tan (\pi / 2) \rightarrow \infty$ ]. As shown in Fig. 1b, it is further assumed that the streamlines in the fracture zone are nearly parallel to the sloping bed (Boussinesq 1877). Applying the mass balance principle to the control volume gives

$\frac{\partial q_{l}}{\partial l}+\frac{\partial q_{y}}{\partial y}+S \cos \alpha \frac{\partial h}{\partial t}=0$

where $S$ is the storage coefficient of the fracture zone. The symbol $q_{l}\left[\mathrm{~L}^{2} / \mathrm{T}\right]$ represents the Darcy flow rate per unit fracture zone width along the $l$-direction, as defined by

$q_{l}=-K b \cos \alpha \frac{\partial h}{\partial l}=-K b \cos \alpha\left(\frac{\partial P}{\partial l}+\tan \alpha \frac{\partial x}{\partial l}\right)$

The symbol $q_{y}\left[\mathrm{~L}^{2} / \mathrm{T}\right]$ represents the Darcy flow rate per unit fracture zone width along the $y$-direction, as defined by

$q_{y}=-K b \cos \alpha \frac{\partial h}{\partial y}=-K b \cos \alpha \frac{\partial P}{\partial y}$

The flow equation in the fracture zone is formulated on the horizontal $x-y$ plane. This is done by first introducing $\partial P / \partial l=\cos \alpha \partial P / \partial x$ and $\partial x / \partial l=\cos \alpha$ to Eq. (3). Substituting the resultant equation for $q_{l}$ along with Eq. (4) into Eq. (2) yields the desired flow equation

$T \cos ^{2} \alpha \frac{\partial^{2} P}{\partial x^{2}}+T \frac{\partial^{2} P}{\partial y^{2}}=S \frac{\partial P}{\partial t}$

which can be written as

$\cos ^{2} \alpha \frac{\partial^{2} P}{\partial x^{2}}+\frac{\partial^{2} P}{\partial y^{2}}=v \frac{\partial P}{\partial t}$

where $v=S / T$ with $T=K b$.

Since the regional flow in the fracture zone has a uniform hydraulic gradient $\partial Z / \partial x=\tan \alpha$, it is known from Eq. (1) that the pressure head before the test does not change in space $(\partial P / \partial x=\partial P / \partial y=0)$; that is $P(x, y, 0)=$ constant. Without loss of generality, the initial condition for Eq. (5) can thus be appropriately prescribed as

$P(x, y, 0)=0$

The fracture zone is modeled as having an infinite extent. This assumption is invoked based on the consideration that the slug test is initiated by limiting the initial water level drop $H_{0}$ less than $0.5 \mathrm{~m}$ in order to secure a hydrostatic water pressure response of $H(t)$; e.g., see Butler et al. (2003), 
Chen et al. (2012). For $H_{0}<0.5 \mathrm{~m}$, the radius of influence of the slug testing flow may not reach any of the hydrogeological boundaries of the finite fracture zone, and thus the fracture zone can be assumed to have an infinite extent. However, if $H(t)$ measured exhibits the interference from a hydrogeological boundary, the well-known image well method can be applied to deal with the boundary effect. The outer boundary conditions for Eq. (5) are set forth as

$P(|x| \rightarrow \infty,|y| \rightarrow \infty, t)=0$

Due to the dipping angle, both $h(x, y, t)$ and its hydraulic gradient are asymmetric with respect to the test well during the slug test. Note that Eq. (5) is mathematically equivalent to the governing equation of groundwater flow in a homogeneous anisotropic aquifer under the confined condition when $T \cos ^{2} \alpha$ is visualized as $T_{x}$ and $T$ as $T_{y}$. Hantush (1966) investigated the constant-rate pumping problem in a homogeneous and anisotropic leaky aquifer where the pumping well is assumed to be a line sink (i.e., $r_{w} \rightarrow 0$ ), and indicated that the flux around the well varies with the flow directions because of aquifer anisotropy [e.g., see his Eq. (11)]. Similarly, the flux around the well varies with the flow directions in the current problem and the mass flow rate continuity across the test well test section can be formulated as

$\left.\int_{0}^{2 \pi} r_{w} T \frac{\partial h}{\partial r}\right|_{r=r_{w}} d \theta=\pi r_{c}^{2} \frac{d H}{d t}$

where $r^{2}=x^{2}+y^{2} \quad$ with $x=r \cos \theta, \quad y=r \sin \theta, \quad$ and $\theta=\tan ^{-1}(y / x)$. Writing Eq. (1) in terms of $r$ and $\theta$ renders $\partial h / \partial r=\partial P / \partial r+\cos \theta \tan \alpha$. Substituting this result into Eq. (8) yields

$\left.T r_{w} \int_{0}^{2 \pi} \frac{\partial P}{\partial r}\right|_{r=r_{w}} d \theta+T r_{w} \tan \alpha \int_{0}^{2 \pi} \cos \theta d \theta=\pi r_{c}^{2} \frac{d H}{d t}$

where $\operatorname{Tr}_{w} \tan \alpha \int_{0}^{2 \pi} \cos \theta d \theta=0$, indicating that the net flow rate of the regional flow entering and leaving the test section is zero. As a result, the boundary condition of the testing well is

$\left.\operatorname{Tr}_{w} \int_{0}^{2 \pi} \frac{\partial P}{\partial r}\right|_{r=r_{w}} d \theta=\pi r_{c}^{2} \frac{d H}{d t}$

Equations (5) - (7) and (9b) form the pressure head variation model in the fracture zone due to the slug test on the horizontal $x-y$ plane. The model solution determination is made easier using an appropriate polar coordinate system, which is established through the following two steps. First, letting $x^{\prime}=x / \cos \alpha$ enables us to express Eq. (5) in its standard Laplacian form $\partial^{2} P / \partial x^{\prime 2}+\partial^{2} P / \partial y^{2}=v \partial P / \partial t$. Second, this Lapacian equation for $P\left(x^{\prime}, y, t\right)$ is transformed to the typical radial flow equation as

$\frac{\partial^{2} P}{\partial r^{\prime 2}}+\frac{1}{r^{\prime}} \frac{\partial P}{\partial r^{\prime}}=v \frac{\partial P}{\partial t}$

where $r^{\prime 2}=x^{\prime 2}+y^{2}, \quad x^{\prime}=r^{\prime} \cos \theta^{\prime}, \quad y=r^{\prime} \sin \theta^{\prime}, \quad$ and
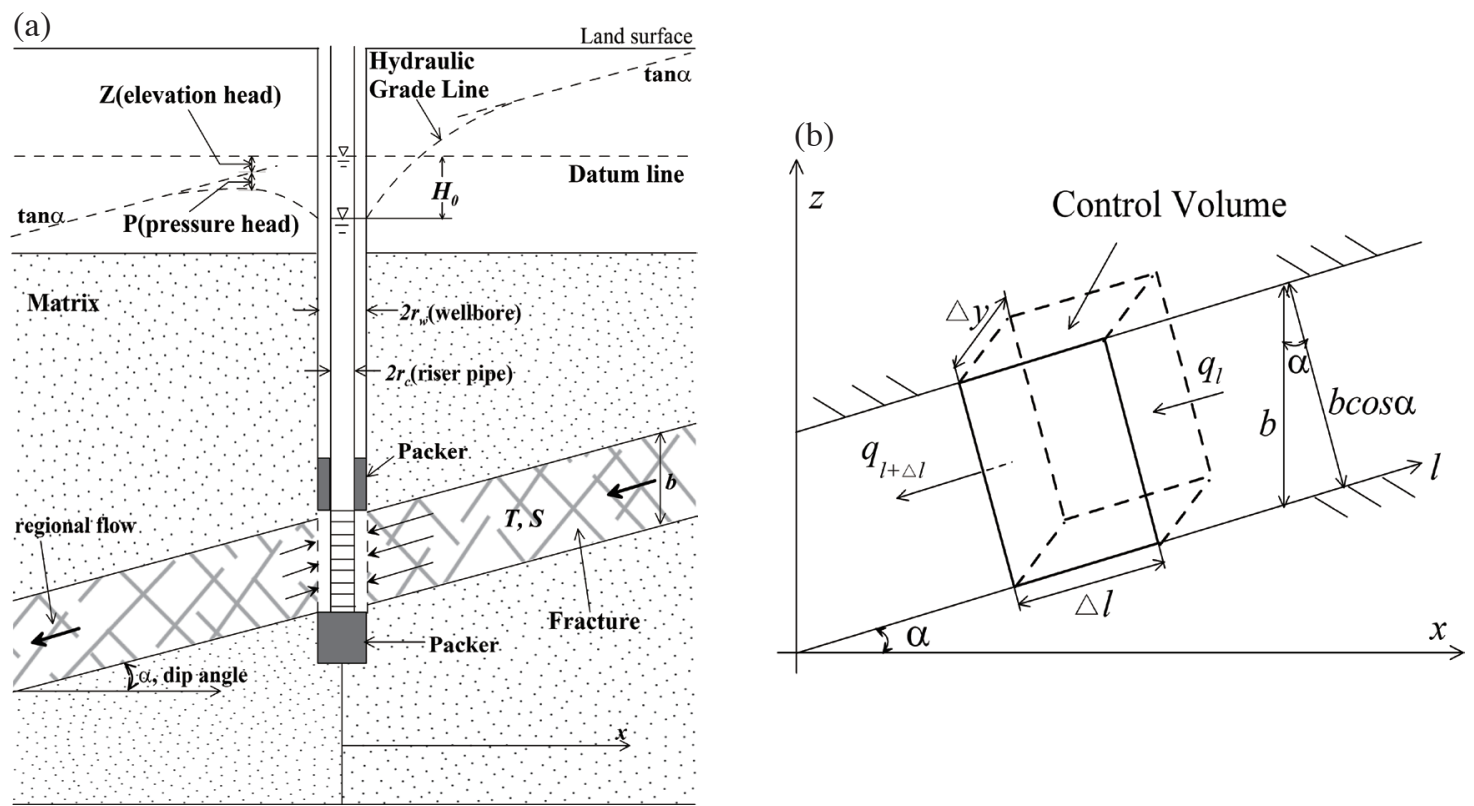

Fig. 1. (a) Schematics of a double-packer slug test in a dip angle $\alpha$ fracture zone, which induces a uniform regional flow in a constant hydraulic gradient of $\tan \alpha$. (b) The control volume diagram for deriving the flow equation. 
$\theta^{\prime}=\tan ^{-1}\left(y / x^{\prime}\right)$. On the $r^{\prime}-\theta^{\prime}$ plane, Eqs. (6) and (7) are

$P\left(r^{\prime}, 0\right)=0$

$P\left(r^{\prime} \rightarrow \infty, t\right)=0$

While the well geometry on the $x-y$ plane is a circle $\left(x^{2}+y^{2}=r_{w}^{2}\right)$, it is elongated into an ellipse $\left(x^{\prime 2} \cos ^{2} \alpha+y^{2}=r_{w}{ }^{2}\right)$ on the $x^{\prime}-y$ plane. As derived in the Appendix, this ellipse on the $r^{\prime}-\theta^{\prime}$ plane is described using the equation of $r^{\prime}=r_{w} / \lambda\left(\theta^{\prime}\right)$ with $\lambda\left(\theta^{\prime}\right)=\sqrt{\cos ^{2} \theta^{\prime} \cos ^{2} \alpha+\sin ^{2} \theta^{\prime}}$. Correspondingly the boundary condition of Eq. (9b) is modified to (see the appendix for a more detailed derivation)

$\left.\operatorname{Tr}_{w} \cos \alpha \int_{0}^{2 \pi} \frac{1}{\lambda^{3}\left(\theta^{\prime}\right)} \frac{\partial P}{\partial r^{\prime}}\right|_{r^{\prime}=r_{w} / \lambda\left(\theta^{\prime}\right)} d \theta^{\prime}=\pi r_{c}^{2} \frac{d H}{d t}$

As stated earlier, the dipping angle cannot be $\pi / 2$, so $\lambda\left(\theta^{\prime}\right)$ is finite for $0 \leq \alpha<\pi / 2$ and lies in $0<\cos \alpha \leq \lambda\left(\theta^{\prime}\right) \leq 1$. As a result, the integration for Eq. (13) exists for $0 \leq \alpha<\pi / 2$. For a horizontal fracture $(\alpha=0)$, $\lambda\left(\theta^{\prime}\right)=1$ and the test well recovers its circular geometry. Eqs. (10) - (13) are used to determine the solution for the pressure head distribution.

Now we proceed to deal with the slug test model for $H(t)$. It is recognized that for a relatively low-K condition, the water level in the riser pipe recovers slowly and $H(t)$ is considered to be instantaneously equilibrated to $h_{w}(t)$, the averaged value of the pressure head in the aquifer around the wellbore of the test section. The solution obtained for $h_{w}(t)$ is therefore set equal to $H(t)$. For a relatively high-K condition, however, the water level in the riser pipe recovers relatively fast and $H(t)$ is oscillatory due to the significant inertial force. In this event, $H(t)$ is not the same as $h_{w}(t)$, and they can be related to each other through the following linearized momentum equation (e.g., Van der Kamp 1976; Kipp 1985; Butler 1998)

$$
\frac{L_{e}}{g} \frac{d^{2} H}{d t^{2}}+H=h_{w}(t)
$$

where

$$
h_{w}(t)=\frac{1}{2 \pi} \int_{0}^{2 \pi} P\left(r_{w}, t\right) d \theta=\frac{\cos \alpha}{2 \pi} \int_{0}^{2 \pi} \frac{P\left[r_{w} / \lambda\left(\theta^{\prime}\right), t\right]}{\lambda^{2}\left(\theta^{\prime}\right)} d \theta^{\prime}(
$$

in which the averaged elevation head around the test section wellbore vanishes because of $r_{w} \tan \alpha \int_{0}^{2 \pi} \cos \theta d \theta=0$. The initial conditions for Eq. (14) are prescribed as

$H(t=0)=H_{0}$

$$
\left.\frac{d H}{d t}\right|_{t=0}=0
$$

where $H_{0}$ is the slug test initial head drop. The mathematical model of interest consists of Eqs. (10) - (17). As Eq. (14) is typical of free oscillation, it is valid for either the underdamped condition where the solution is oscillatory or the over damped condition where the solution is non-oscillatory (e.g., see Wylie and Barrett 1982). That is, we use the above model for both the relatively high- and low-K conditions.

\subsection{Model Solution}

The model solution will be determined using appropriate dimensionless parameters. The dimensionless mathematical model is

$\frac{\partial^{2} \eta_{P}}{\partial \rho^{\prime 2}}+\frac{1}{\rho^{\prime}} \frac{\partial \eta_{P}}{\partial \rho^{\prime}}=\sigma \frac{\partial \eta_{P}}{\partial \tau} \quad \lambda^{-1}\left(\theta^{\prime}\right) \leq \rho^{\prime}<\infty$

$\eta_{P}\left(\rho^{\prime}, \tau=0\right)=0$

$\eta_{P}\left(\rho^{\prime} \rightarrow \infty, \tau\right)=0$

$\left.\frac{\cos \alpha}{2 \pi} \int_{0}^{2 \pi} \frac{1}{\lambda^{3}\left(\theta^{\prime}\right)} \frac{\partial \eta_{P}}{\partial \rho^{\prime}}\right|_{\rho^{\prime}=\lambda^{-1}\left(\theta^{\prime}\right)} d \theta^{\prime}=\frac{d w}{d \tau}$

$\phi^{2} \frac{d^{2} w}{d \tau^{2}}+w=\eta_{w}(\tau)$

$w(\tau=0)=1$

$\left.\frac{d w}{d \tau}\right|_{\tau=0}=0$

where $\eta_{w}(\tau)$ represents the dimensionless $h_{w}(t)$ defined as

$\eta_{w}(\tau)=\frac{\cos \alpha}{2 \pi} \int_{0}^{2 \pi} \frac{\eta_{P}\left[\lambda^{-1}\left(\theta^{\prime}\right), \tau\right]}{\lambda^{2}\left(\theta^{\prime}\right)} d \theta^{\prime}$

And $\tau=2 T t / r_{c}^{2}$ is the dimensionless time, $\rho^{\prime}=r^{\prime} / r_{w}$ is the dimensionless $r^{\prime}, \eta_{P}\left(\rho^{\prime}, \tau\right)=P\left(r^{\prime}, t\right) / H_{0}$ is the dimensionless pressure head in the fracture zone, $\sigma=2 r_{w}{ }^{2} S / r_{c}{ }^{2}$ is the dimensionless storage coefficient, $w(\tau)=H(t) / H_{0}$ is the dimensionless test response, $\phi=2 T \sqrt{L_{e} / g} / r_{c}^{2}$ is the dimensionless transmissivity, and $L_{e}$ is the effective water column length in the test well.

Applying the Laplace transform with respect to $\tau$ to Eqs. (18) - (21) yields

$\frac{\partial^{2} \bar{\eta}_{P}}{\partial \rho^{\prime 2}}+\frac{1}{\rho^{\prime}} \frac{\partial \bar{\eta}_{P}}{\partial \rho^{\prime}}-\sigma s \bar{\eta}_{P}=0$ 
$\bar{\eta}_{P}(\infty, s)=0$

$\left.\frac{\cos \alpha}{2 \pi} \int_{0}^{2 \pi} \frac{1}{\lambda^{3}\left(\theta^{\prime}\right)} \frac{\partial \bar{\eta}_{P}}{\partial \rho^{\prime}}\right|_{\rho^{\prime}=\lambda^{-1}\left(\theta^{\prime}\right)} d \theta^{\prime}=s \bar{w}-1$

where $s$ is the Laplace transform variable and $\bar{\eta}_{P}\left(\rho^{\prime}, s\right)$ represents the dimensionless pressure head $\eta_{P}\left(\rho_{\infty}^{\prime}, \tau\right)$ after the Laplace transform is defined as $\bar{\eta}_{P}\left(\rho^{\prime}, s\right)=\int e^{-s \tau} \eta_{P}\left(\rho^{\prime}, \tau\right) d \tau$ (e.g., see Kreyszig 1998). The solution to Eqs. (26) - (28) is

$\bar{\eta}_{P}\left(\rho^{\prime}, s\right)=-\frac{2 \pi(s \bar{w}-1)}{\cos \alpha \sqrt{\sigma s} f_{1}(s)} K_{0}\left(\sqrt{\sigma s} \rho^{\prime}\right)$

where

$f_{1}(s)=\int_{0}^{2 \pi} \frac{K_{1}\left[\sqrt{\sigma s} / \lambda\left(\theta^{\prime}\right)\right]}{\lambda^{3}\left(\theta^{\prime}\right)} d \theta^{\prime}$

and $K_{0}(x), K_{1}(x)$ are the modified Bessel functions of the second order zero kind and one, respectively. Note that $K_{1}\left[\sqrt{\sigma s} / \lambda\left(\theta^{\prime}\right)\right] / \lambda^{3}\left(\theta^{\prime}\right)$ remains finite for $0 \leq \theta^{\prime} \leq 2 \pi$, and the evaluation of $f_{1}(s)$ can be numerically carried out without difficulty.

$w(\tau)$ is determined using Eqs. (22) - (24). The $\eta_{w}(\tau)$ Laplace transform in Eq. (25) is obtained by substituting Eq. (29) into Eq. (25). In a straightforward manner the Laplace-domain solution for $w(\tau)$ is then

$\bar{w}(s)=\frac{s+g(s) / \phi^{2}}{s^{2}+g(s) s / \phi^{2}+1 / \phi^{2}}$

where

$g(s)=\frac{f_{2}(s)}{\sqrt{\sigma s} f_{1}(s)}$

and

$f_{2}(s)=\int_{0}^{2 \pi} \frac{K_{0}\left[\sqrt{\sigma s} / \lambda\left(\theta^{\prime}\right)\right]}{\lambda^{2}\left(\theta^{\prime}\right)} d \theta^{\prime}$

As $\sqrt{\sigma s} / \lambda\left(\theta^{\prime}\right) \neq 0, K_{1}\left[\sqrt{\sigma s} / \lambda\left(\theta^{\prime}\right)\right] / \lambda^{2}\left(\theta^{\prime}\right)$ remain finite for $0 \leq \theta^{\prime} \leq 2 \pi$, and the $f_{2}(s)$ evaluation can be numerically carried out without difficulty. When $\alpha=0$, Eq. (31) becomes identical to its counterpart in a horizontal fracture zone [e.g., see Eq. (16) from Kipp (1985) while setting both the skin effect and water surface initial velocity to zero]. The Laplace inverse of Eq. (31) gives the solution for $w(\tau)$. The Laplace inverse is numerically calculated using the De Hoog et al. (1982) method.

\section{THEORETICAL ANALYSIS}

The theoretical analysis focuses on how the dip angle $\alpha$ influences the test response $w(\tau)$ under various $\sigma$ and $\phi$. Figure 2 pertains to the relatively low-K non-oscillatory response conditions and Fig. 3 to the relatively high-K oscillatory response conditions. For the set $\sigma$ and $\phi$, the symbol $\alpha^{*}$ denotes the upper limit below which the dip angle effect can be neglected. For the same set $\sigma$ and $\phi$, the test response recovers faster when the dip angle becomes larger, as shown in Fig. 2a. This is observed in the solid curves group associated with $\sigma=0.01$ and $\phi=0.05$, where $w(\tau)$ of $\alpha=85^{\circ}$ recovers faster than does that of $\alpha=70^{\circ}$ and $w(\tau)$ of $\alpha=70^{\circ}$ recovers faster than does that of $\alpha=34^{\circ}$. This faster recovery is attributed to the fact that the wellbore flow rate $q^{*}(\tau)$ associated with the slug test increases as $\alpha$ increases, as shown in Fig. 2b. The determination of $q^{*}(\tau)=d w / d \tau$ is made by numerically inverting its Laplace-domain counterpart, Eq. (28). When $\phi$ remains unchanged, $\alpha^{*}$ increases as $\sigma$ decreases, as indicated by the group of dashed curves of $\phi=0.05$, which show $\alpha^{*}$ increases from $34-45^{\circ}$ as $\sigma=0.01$ decreases to $10^{-4}$. When $\sigma$ remains constant, $\alpha^{*}$ is not significantly influenced by the variation of $\phi$. This is observed by noting $\alpha^{*}$ remains as $45^{\circ}$ for both the dashed curve $(\phi=0.05)$ and the broken curve ( $\phi=0.5$ ), when $\sigma$ is kept to be $10^{-4}$.

For the relatively high-K conditions, the oscillation amplitude increases as $\alpha$ increases while the period shows little change, as shown in Fig. 3, where the solid curve amplitude of $\alpha=85^{\circ}$ is greater than that of $\alpha=70^{\circ}$ and the solid curve amplitude of $\alpha=70^{\circ}$ is greater than that of $\alpha=34^{\circ}$. This is because a larger dip angle causes smaller $\eta_{w}(\tau)$. Using an electric analog model, Bredehoeft et al. (1966) demonstrated that $h_{w}(t)$ functions as a frictional force to the oscillatory $H(t)$. Below it further proves that $h_{w}(t)$ indeed introduces a damping force to $H(t)$. As far as $\alpha^{*}$ is concerned, it decreases as $\sigma$ increases and has little influence from the variation of $\phi$; the same as for the relatively low-K conditions.

We determine $\alpha^{*}$ for various values of $\sigma$, and the results are plotted in Fig. 4. Using regression analysis an empirical relation for $\alpha^{*}$ (in radian) as a function of $\sigma$ is determined as

$\alpha^{*}=-1.95 \sigma^{0.023}+2.36$

As $S$ is unknown a priori while $\alpha$ is usually measured before the test, Eq. (34) is more useful to "predict" whether or not the test response would be influenced by the dip angle. Take the well field site in the Cenozoic folded sandstone formation for example. It is known that $S$ of sandstone rock is approximately $10^{-4}-10^{-2}$ (Singhal and Gupta 2010). As $r_{w}=0.0508 \mathrm{~m}$ and $r_{c}=0.0135 \mathrm{~m}$, the values of $\sigma\left(=2 r_{w}{ }^{2} S / r_{c}{ }^{2}\right)$ range from $2.83 \times 10^{-3}$ to 0.283 . Equation (34) then gives $26^{\circ} \leq \alpha^{*} \leq 37^{\circ}$. That is, the dip angle effect can be quite safely neglected in 

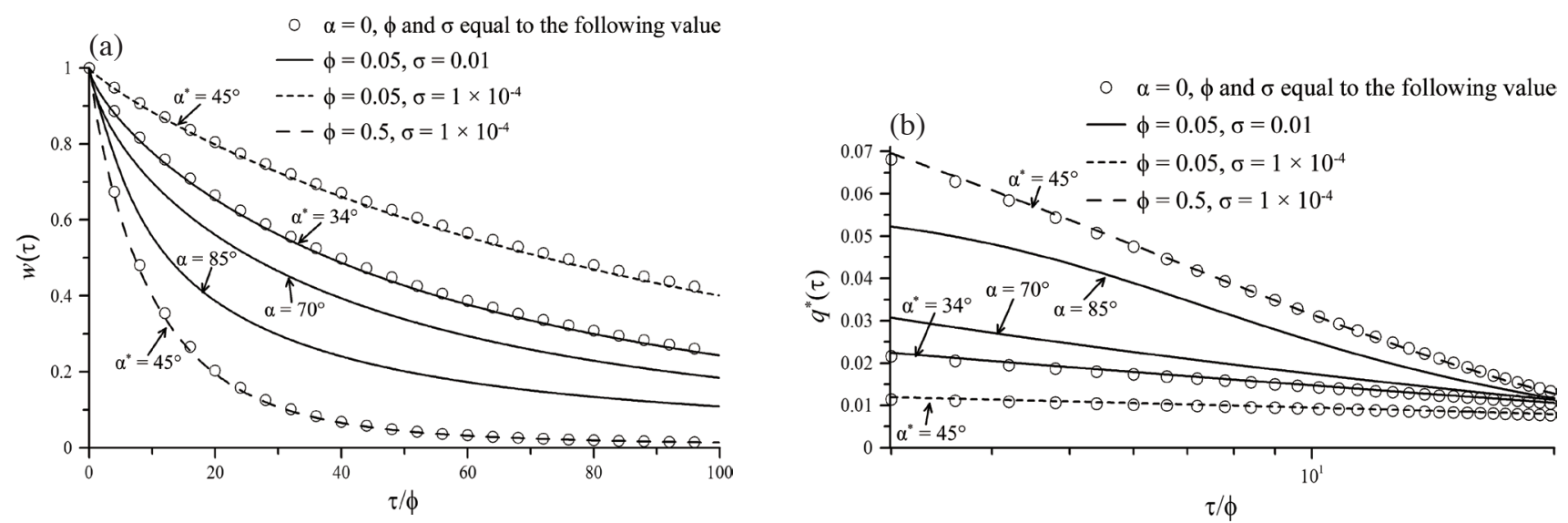

Fig. 2. Influence of $\alpha$ on the test response for relatively low-K conditions: (a) the head recovers faster for a larger $\alpha$; (b) the wellbore flow rate increases with increasing $\alpha$. The limiting angle $\alpha^{*}$ increases as $\sigma$ decreases, while it remains relatively insensitive to $\phi$ for the same $\sigma$.

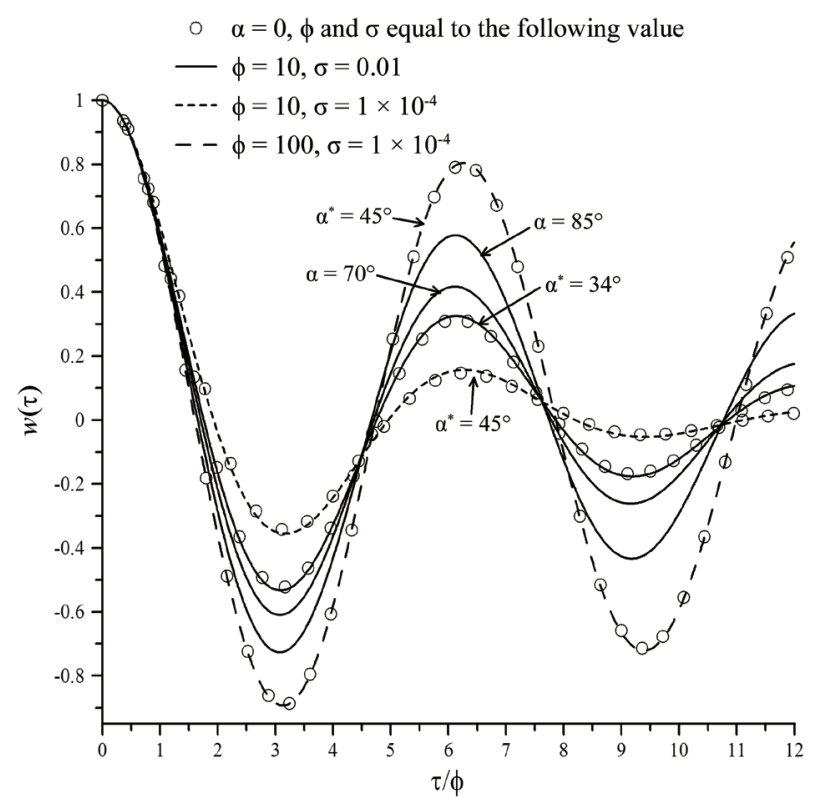

Fig. 3. Influence of $\alpha$ on the test response for a relatively high-K condition: oscillation amplitude increases with increasing $\alpha$. The limiting angle $\alpha^{*}$ increases as $\sigma$ decreases, while it remains relatively insensitive to $\phi$ for the same $\sigma$.

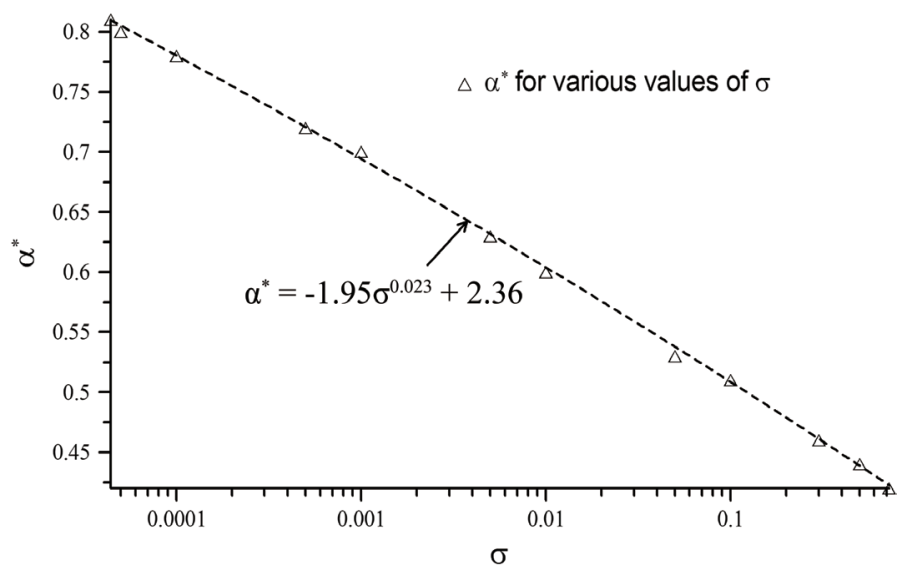

Fig. 4. The empirical relationship for $\alpha^{*}$ as a function of $\sigma$. 
the data analysis if $\alpha$ measures less than $26^{\circ}$, and should be included if $\alpha$ measures greater than $37^{\circ}$. When $\alpha$ is measured between $37^{\circ}$ and $26^{\circ}$, the dip angle effect may or may not be negligible. For practical purposes the dip angle effect should be considered in the data analysis when $\alpha>26^{\circ}$.

The above theoretical analysis focuses primarily on the test response in the test well. For a cross-borehole slug test, the test response can be transmitted from the test well to the nearby observation wells. The test response analysis in an observation well requires the response solution in an observation well and the momentum balance in the observation well (e.g., see Zhan and Butler 2003; Audouin and Bodin 2008). The flow field complexity is primarily due to the fact that the test response in the fracture zone changes with distance as well as direction. Observation well response modeling and data analysis will be presented elsewhere.

\section{DATA ANALYSIS}

In data analysis, the effective water length $L_{e}$ is recommended to be treated as a fitting parameter (e.g., Kabala et al. 1985; Butler et al. 2003; Chen 2006). For a horizontal formation $L_{e}$ is defined using the following equation

$$
L_{e}=\frac{g}{\omega^{2}+0.25 \beta^{2}}
$$

where $\omega\left[T^{-1}\right]$ and $\beta\left[T^{-1}\right]$ are the frequency and the damping coefficient of oscillation, respectively (Van der Kamp 1976). Both $\omega$ and $\beta$ can be estimated from the measured test response (Chen 2006; Chen and $\mathrm{Wu} 2006$ ), and thus $L_{e}$ can be uniquely evaluated using the field data. Whether or not $L_{e}$ is so determined can be used for a sloping fracture zone depending on whether Eq. (35) is valid for a sloping formation. To this end, we start with the oscillatory response solution in a horizontal formation (e.g., Wylie and Barrett 1982; Springer and Gelhar 1991)

$$
\frac{w(t)}{w_{0}}=e^{-\beta t / 2}\left[\cos (\omega t)+\frac{\beta}{2 \omega} \sin (\omega t)\right]
$$

In terms of the dimensionless parameters used in this paper, the Laplace transform of Eq. (36) is

$$
\bar{w}(s)=\frac{s+\beta^{*}}{s^{2}+\beta^{*} s+\left(0.25 \beta^{* 2}+\omega^{* 2}\right)}
$$

where $\beta^{*}=\beta r_{c}^{2} / 2 T$ as the dimensionless damping coefficient, and $\omega^{*}=\omega r_{c}^{2} / 2 T$ as the dimensionless frequency. Comparing Eqs. (31) to (37) discloses the following two facts. First, the $g(s) / \phi^{2}$ term in Eq. (31) is equivalent to the damping coefficient $\beta^{*}$ in Eq. (37). Given that $g(s) / \phi^{2}$ is from the Laplace transform of $h_{w}(t)$, the electric analog observation by Bredehoeft et al. (1966), as discussed above, is confirmed. Second, the constant term of $1 / \phi^{2}$ in Eq. (31) is equal to the constant term of $0.25 \beta^{* 2}+\omega^{* 2}$ in Eq. (37). The dimensional analysis of this equality proves Eq. (35) is also valid for a non-zero dip angle. Therefore, $L_{e}$ is evaluated using Eq. (35) with $\omega$ and $\beta$ determined using the field data is applicable to the sloping fracture zone case. After $L_{e}$ is known the two parameters $T$ and $S$ can be determined using the least root mean square error fitting method.

There is a well field (Fig. 5) in a Cenozoic folded sandstone formation overlain by a weathered zone about $20 \mathrm{~m}$ in thickness in northern Taiwan. This site was about $15 \mathrm{~m}$ above a nearby stream and had seven wells (C, N, E, S, W, $\mathrm{W} 1$, and W2). The layout of the wells is shown in Fig. 5. All of the wells were 4-inch in diameter $\left(r_{w}=0.0508 \mathrm{~m}\right)$ and cased in the weathered zone and uncased as an open borehole from 20 - $50 \mathrm{~m}$ in sandstone. Wells W1 and W2 had not been in use due to certain construction problems. The image taken by a borehole optical televiewer in a well reveals that at $31 \mathrm{~m}$ depth a fracture zone exists consisting of a set of fractures distributed over the $0.1 \mathrm{~m}$ packed interval and dipping to the northwest $\left(344^{\circ}\right)$ with a dip angle of $47^{\circ}$. The actual extent of this fracture zone is unknown. A doublepacker slug test was conducted at well $\mathrm{C}$ in the $\alpha=47^{\circ}$ dip angle fracture zone. No response was observed in the four surrounding wells during the test. Therefore, it is appropriate to assume the sloping fracture zone to be infinite in extent for the test. In general, the current model assumptions adequately satisfy the field conditions.

The slug test was initiated pneumatically with an initial head drop of $H_{0}=0.48 \mathrm{~m}$. The pressure transducer for $H(t)$ measurement is placed $0.5 \mathrm{~m}$ below the initial water level. The measured $H(t)$ is nearly associated with hydrostatic water pressure and the linear model of Eq. (14) is adequate (e.g., Butler et al. 2003; Chen et al. 2012). Since the dip angle is greater than the upper limit of $\alpha^{*}=37^{\circ}$, as determined earlier, the data analysis needs to take into account the dip angle effect. The fracture zone thickness is $b=0.1$ $\mathrm{m}$. The effective water column length $L_{e}$ is determined using the method given by (Chen 2006), as shown in Fig. 6. The frequency is determined as $\omega=2 \pi /\left(t_{k+2}-t_{k}\right)$, where $t_{k}$ is the time corresponding to the occurrence of the $k^{\text {th }}$ extremity (peak or valley of the oscillation), where the subscript $k=1,2, \ldots$. As indicated in Fig. $6, t_{k+2}-t_{k}=8.74 \mathrm{sec}$ gives $\omega=0.72 \mathrm{sec}^{-1}$. The damping coefficient is calculated by $\beta=4 \ln \left(H_{k} / H_{k+1}\right) /\left(t_{k+2}-t_{k}\right)$, where $H_{k}$ denotes the $k^{\text {th }}$ extremity displacement. As $H_{k} / H_{k+1}=1.97, \beta$ is $0.31 \mathrm{sec}^{-1}$. As a result, $L_{e}=18.2 \mathrm{~m}$, as determined using Eq. (35). Using Eq. (32) and $L_{e}=18.2 \mathrm{~m}$, the best oscillatory test response fit, as shown by the solid curve, gives $T=4.12 \times 10^{-4} \mathrm{~m}^{2} \mathrm{~s}^{-1}$ and $S=5.34 \times 10^{-4}$.

Now we proceed to investigate the effect of neglecting the dip angle in data analysis. This is done by setting $\alpha=0^{\circ}$ 
in Eq. (31) when analyzing the field data. As a result, the best fit represented by the dashed curve in Fig. 6 is associated with $T=5.24 \times 10^{-4} \mathrm{~m}^{2} \mathrm{~s}^{-1}$ and $S=2.53 \times 10^{-4}$. Although the solid and dashed curves are nearly coincident, the $T$ and $S$ estimates are quite different. The calculated dip angle negligence causes a $27 \%$ transmissivity over estimation and a $53 \%$ storage coefficient under estimation. Furthermore, we used $S=5.34 \times 10^{-4}$ and Eq. (34) to obtain $\alpha^{*}=34^{\circ}$, which is indeed less than $47^{\circ}$, supporting using the current model to analyze the field data.

The sensitivity of the current model to $T$ (for a given $\alpha$ and a given $S$ ) is demonstrated in Fig. 7a, where three $T$ values, $5.24 \times 10^{-4} \mathrm{~m}^{2} \mathrm{~s}^{-1}, 4.1 \times 10^{-4}$ and $3.0 \times 10^{-4} \mathrm{~m}^{2} \mathrm{~s}^{-1}$ are used to represent a $\pm 27 \%$ change in transmissivity from $4.1 \times 10^{-4} \mathrm{~m}^{2} \mathrm{~s}^{-1}$. A $\pm 27 \%$ change in $T$ causes a significant variation in the calculated test response. Figure $7 \mathrm{~b}$ shows the model solution sensitivity to $S$, where three values for $S=8.15 \times 10^{-4}, 5.3 \times 10^{-4}$, and $2.53 \times 10^{-4}$ are used to represent a $\pm 53 \%$ variation in the storage coefficient from the one of $5.3 \times 10^{-4}$. In comparison to Fig. $7 \mathrm{a}$ it is clear that the current model is less sensitive to $S$.

\section{CONCLUSIONS}

Slug test models in the literature assume a horizontal formation. This research developed a new slug test model that takes the dip angle effects into account. The dip angle

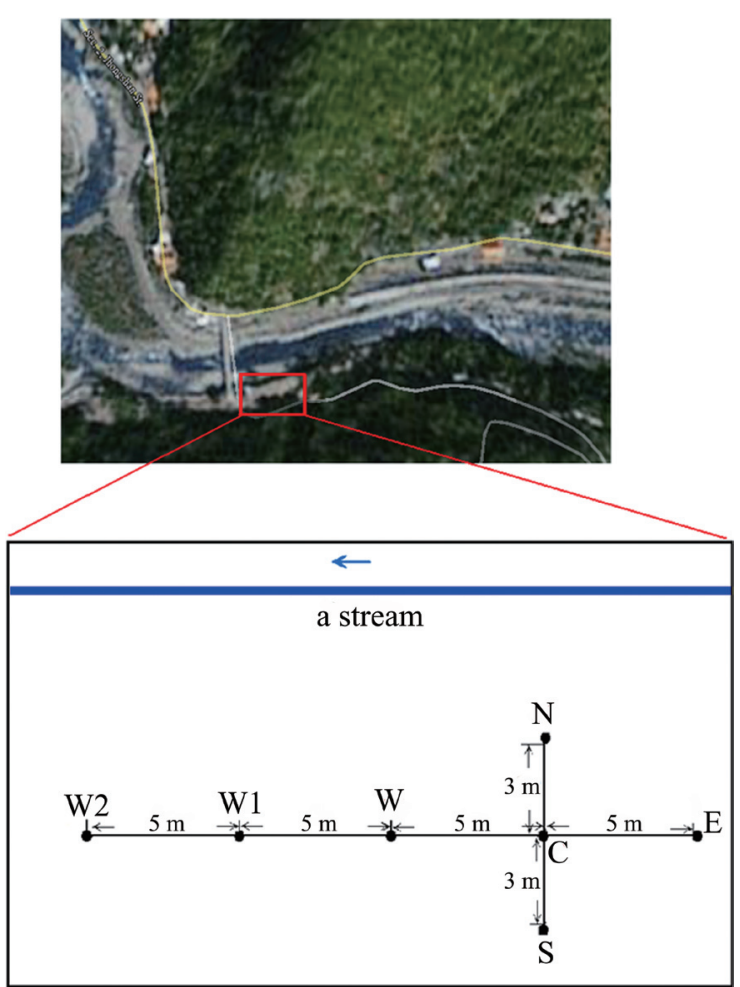

Fig. 5. Schematics of the well field in northern Taiwan, which has seven wells (C, N, E, S, W, W1, and W2). is assumed to cause a downward regional flow in the fracture zone. The problems associated with an upward regional flow will be presented elsewhere. The Laplace-domain solution was determined for both the oscillatory and non-oscillatory test response. When the fracture zone transmissivity is relatively low (i.e., $T<1.0 \times 10^{-4} \mathrm{~m}^{2} \mathrm{~s}^{-1}$ ), a larger dip angle causes a faster non-oscillatory test response recovery. When the fracture zone transmissivity is relatively high (i.e., $T>1.0 \times 10^{-4} \mathrm{~m}^{2} \mathrm{~s}^{-1}$ ), a larger dip angle causes an increase in oscillatory test response amplitude. It is proven that the effective water length, an important parameter necessary for oscillatory test response analysis, is independent of the dip angle and can be evaluated using the methods currently available for horizontal formations.

In general, neglecting the dip angle may lead to hydraulic conductivity over estimation and storage coefficient under estimation. The dip angle effect is more pronounced for a larger storage coefficient, being less sensitive to the change in transmissivity. An empirical relationship as a function of the dimensionless storage coefficient is developed for the limiting dip angle, below which the dip angle effect is negligible. A number of cross-borehole slug tests were conducted in a Cenozoic folded sandstone formation, where a dip angle fracture zone as large as $47^{\circ}$ was measured. The slug test data in the $47^{\circ}$ dip angle fracture zone was analyzed using the current model. Neglecting the dip angle can result in a $27 \%$ transmissivity over estimation and

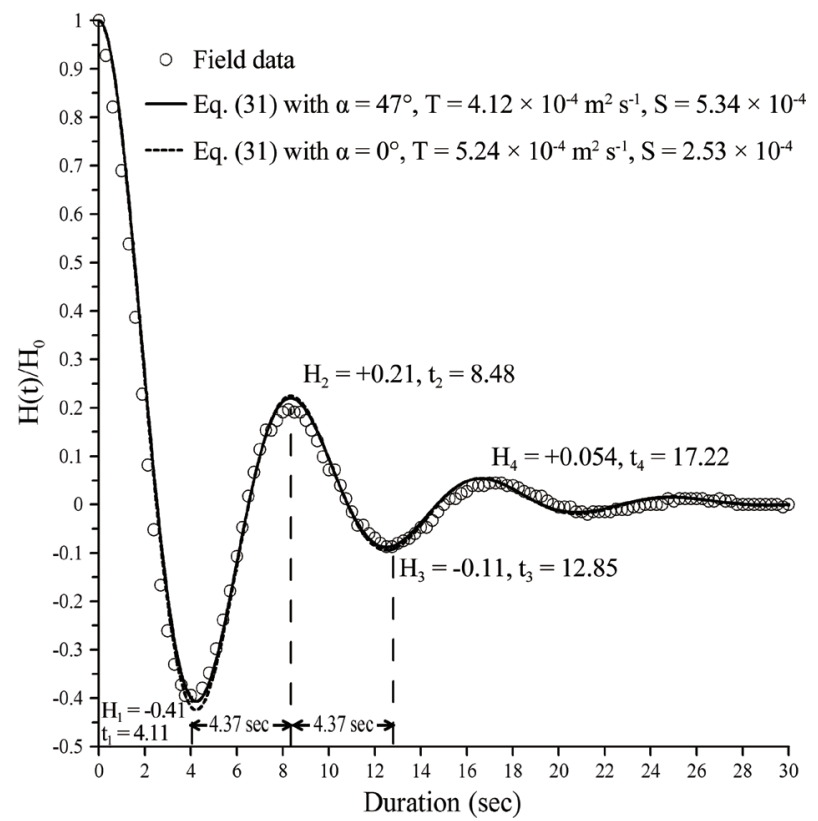

Fig. 6. Analysis of the slug test data in a dip angle equal to $47^{\circ}$ with a fracture zone, where $t_{k}$ and $H_{k}$ are used for the effective water length determination $L_{e}$. The solid $\left(\alpha=47^{\circ}\right)$ and dashed curves $\left(\alpha=0^{\circ}\right)$ are nearly coincident while the $T$ and $S$ estimates are different. 

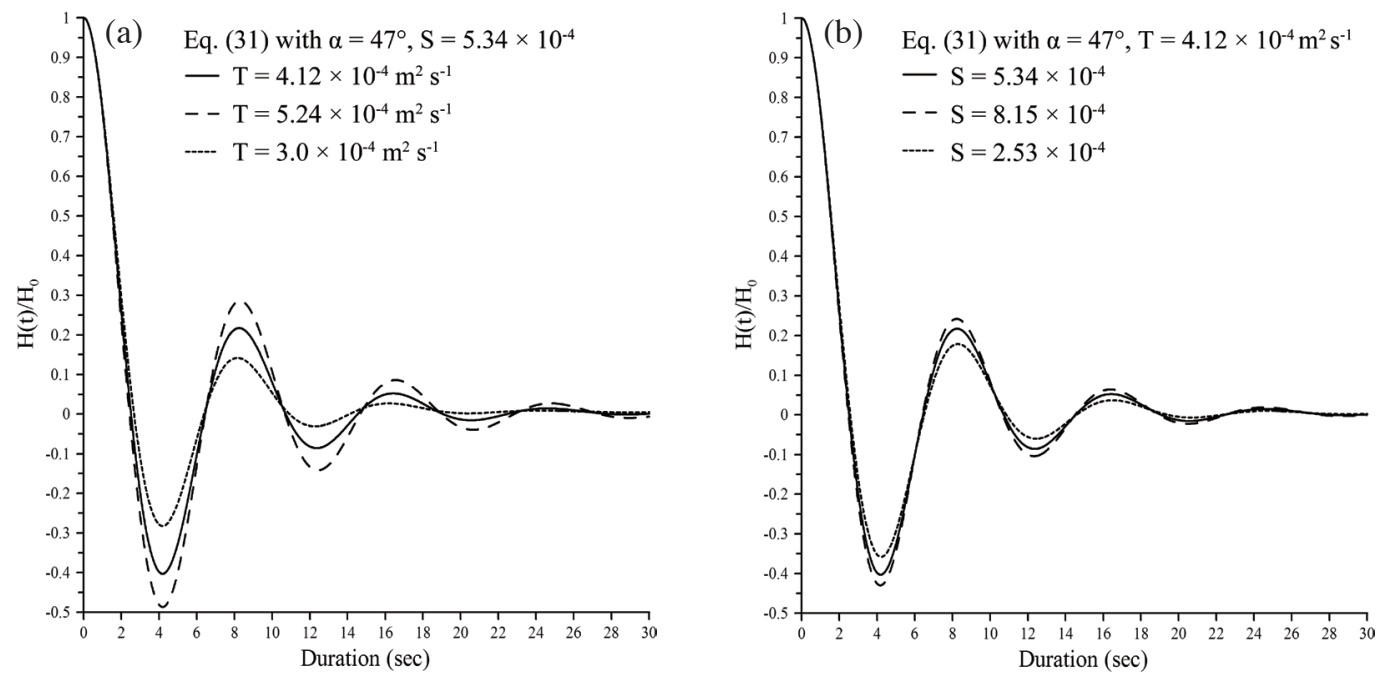

Fig. 7. (a) Sensitivity of the model solution to a $\pm 27 \%$ change in transmissivity. (b) Sensitivity of the current model to a variation of $\pm 53 \%$ in the storage coefficient.

a $53 \%$ storage coefficient under estimation.

Acknowledgements This work was supported by the National Science Council of Taiwan under Grant 100-2116-M008-007 and 101-2116-M-008-007. The first author appreciates the support from National Central University.

\section{REFERENCES}

Alexander, M., S. J. Berg, and W. A. Illman, 2011: Field study of hydrogeologic characterization methods in a heterogeneous aquifer. Ground Water, 49, 365-382, doi: 10.1111/j.1745-6584.2010.00729.x. [Link]

Audouin, O. and J. Bodin, 2008: Cross-borehole slug test analysis in a fractured limestone aquifer. J. Hydrol., 348, 510-523, doi: 10.1016/j.jhydrol.2007.10.021. [Link]

Barker, J. A., 1988: A generalized radial flow model for hydraulic tests in fractured rock. Water Resour. Res., 24, 1796-1804, doi: 10.1029/WR024i010p01796. [Link]

Barker, J. A. and J. H. Black, 1983: Slug tests in fissured aquifers. Water Resour. Res., 19, 1558-1564, doi: 10.1029/WR019i006p01558. [Link]

Barker, J. A., T. E. J. Wright, and B. A. Fretwell, 2000: A pulsed-velocity method of double-porosity solute transport modeling. In: Dassargues, A. (Ed.), Tracers and Modelling in Hydrogeology, Proceedings of TraM'2000, the International Conference on Tracers and Modelling in Hydrogeology, IAHS Publication, No. 262, Liège, Belgium, 297-302.

Black, J. H., 1985: The interpretation of slug tests in fissured rocks. Q.J.Eng. Geol. Hydrogeol., 18, 161-171, doi: 10.1144/GSL.QJEG.1985.018.02.05. [Link]

Boussinesq, M. J., 1877: Essai sur la théorie des eaux cou- rantes. Mém. Présentés par divers savants à l'Acad. Sci. Inst. France, 23, 1-680.

Bredehoeft, J. D., H. H. Cooper, and I. S. Papadopulos, 1966: Inertial and storage effects in well-aquifer systems: An analog investigation. Water Resour. Res., 2, 697-707, doi: 10.1029/WR002i004p00697. [Link]

Butler, J. J., 1998: The Design, Performance, and Analysis of Slug Tests, Lewis Publishers, New York, 252 pp.

Butler, J. J. and X. Zhan, 2004: Hydraulic tests in highly permeable aquifers. Water Resour. Res., 40, W12402, doi: 10.1029/2003WR002998. [Link]

Butler, J. J., E. J. Garnett, and J. M. Healey, 2003: Analysis of slug tests in formations of high hydraulic conductivity. Ground Water, 41, 620-631, doi: 10.1111/j.17456584.2003.tb02400.x. [Link]

Chen, C. S., 2006: An analytic data analysis method for oscillatory slug tests. Ground Water, 44, 604-608, doi: 10.1111/j.1745-6584.2006.00202.x. [Link]

Chen, C. S. and C. R. Wu, 2006: Analysis of depth-dependent pressure head of slug tests in highly permeable aquifers. Ground Water, 44, 472-477, doi: 10.1111/ j.1745-6584.2005.00152.x. [Link]

Chen, C. S., Y. C. Sie, and Y. T. Lin, 2012: A review of the multilevel slug test for characterizing aquifer heterogeneity. Terr. Atmos. Ocean. Sci., 23, 131-143, doi: 10.3319/TAO.2011.10.03.01(Hy). [Link]

Cooper, H. H., J. D. Bredehoeft, and I. S. Papadopulos, 1967: Response of a finite-diameter well to an instantaneous charge of water. Water Resour. Res., 3, 263-269, doi: 10.1029/WR003i001p00263. [Link]

De Hoog, F. R., J. H. Knight, and A. N. Stokes, 1982: An improved method for numerical inversion of Laplace transforms. SIAM J. Sci. Stat. Comput., 3, 357-366, doi: 10.1137/0903022. [Link] 
Dougherty, D. E. and D. K. Babu, 1984: Flow to a partially penetrating well in a double-porosity reservoir. Water Resour. Res., 20, 1116-1122, doi: 10.1029/ WR020i008p01116. [Link]

Grader, A. S. and H. J. Ramey, 1988: Slug-test analysis in double-porosity reservoirs. SPE Formation Evaluation, 3, 329-339, doi: 10.2118/15479-PA. [Link]

Hantush, M. S., 1966: Wells in homogeneous anisotropic aquifers. Water Resour. Res., 2, 273-279, doi: 10.1029/ WR002i002p00273. [Link]

Kabala, Z. J., G. F. Pinder, and P. C. D. Milly, 1985: Analysis of well-aquifer response to a slug test. Water Resour. Res., 21, 1433-1436, doi: 10.1029/WR021i009p01433. [Link]

Kipp, K. L., 1985: Type curve analysis of inertial effects in the response of a well to a slug test. Water Resour. Res., 21, 1397-1408, doi: 10.1029/WR021i009p01397. [Link]

Kreyszig, E., 1998: Advanced Engineering Mathematics, $8^{\text {th }}$ edition, John Wiley and Sons Inc., New York, 1288 pp.

Mateen, K. and H. J. Ramey, 1984: Slug test data analysis in reservoirs with double porosity behavior. SPE California Regional Meeting, 11-13 April, Long Beach, California, 459-468.

McElwee, C. D. and M. A. Zenner, 1998: A nonlinear model for analysis of slug-test data. Water Resour. Res., 34, 55-66, doi: 10.1029/97WR02710. [Link]

McWhorter, D. B. and D. K. Sunada, 1981: Ground-Water Hydrology and Hydraulics, Water Resources Publication, Fort Collins, CO, 290 pp.

Moench, A. F., 1984: Double-porosity models for a fissured groundwater reservoir with fracture skin. Water Resour. Res., 20, 831-846, doi: 10.1029/WR020i007p00831. [Link]

Novakowski, K. S. and G. S. Bickerton, 1997: Borehole measurement of the hydraulic properties of low-permeability rock. Water Resour. Res., 33, 2509-2517, doi: 10.1029/97WR02189. [Link]

Ostendorf, D. W., D. J. DeGroot, P. J. Dunaj, and J. Jakubowski, 2005: A closed form slug test theory for high permeability aquifers. Ground Water, 43, 87-101, doi: 10.1111/j.1745-6584.2005.tb02288.x. [Link]

Ross, H. C. and C. D. McElwee, 2007: Multi-level slug tests to measure 3-D hydraulic conductivity distributions. Nat.Resour.Res., 16, 67-79, doi: 10.1007/s11053-007-9034-9. [Link]

Rozos, E., E. Akylas, and A. D. Koussis, 2015: An automated inverse method for slug tests-over-damped case-in confined aquifers. Hydrolog. Sci. J., 60, 285-293, doi: 10.1080/02626667.2014.892207. [Link]

Sageev, A. and H. J. Ramey, 1986: On slug test analysis in double-porosity reservoirs. SPE Paper 15479, Soc. of Pet. Engrs.

Singhal, B. B. S. and R. P. Gupta, 2010: Applied Hydro- geology of Fractured Rocks, second edition, Springer Netherlands, New York, 237-289, doi: 10.1007/978-90-481-8799-7. [Link]

Springer, R. K. and L. W. Gelhar, 1991: Characterization of large-scale aquifer heterogeneity in glacial outwash by analysis of slug tests with oscillatory response. USGS Water-Recourses Investigation Report 91-4034, Cape Cod, Massachusetts, 36-40.

Van der Kamp, G., 1976: Determining aquifer transmissivity by means of well response tests: The underdamped case. Water Resour. Res., 12, 71-77, doi: 10.1029/ WR012i001p00071. [Link]

Wu, Y. S., 2002: An approximate analytical solution for non-Darcy flow toward a well in fractured media. $W a$ ter Resour. Res., 38, 5-1-5-7.

Wylie, C. R. and L. C. Barrett, 1982: Advanced Engineering Mathematics, $5^{\text {th }}$ edition, McGraw-Hill Inc., New York, US, 1105 pp.

Zhan, X. and J. J. Butler, 2003: Mathematical derivations of semianalytical solutions for hydraulic tests in highly permeable aquifers. Kansas Geological Survey OpenFile Report \#2003-60, Lawrence, KS.

Zlotnik, V. A. and V. L. McGuire, 1998: Multi-level slug tests in highly permeable formations: 1. Modification of the Springer-Gelhar (SG) model. J. Hydrol., 204, 271-282, doi: 10.1016/S0022-1694(97)00128-5. [Link]

Zurbuchen, B. R., V. A. Zlotnik, and J. J. Butler, 2002: Dynamic interpretation of slug tests in highly permeable aquifers. Water Resour. Res., 38, 7-1-7-18, doi: 10.1029/2001WR000354. [Link]

\section{APPENDIX A}

Derivation of Eq. (13) from Eq. (9b). The well circular geometry on the $x-y$ plane needs to be expressed on the $r^{\prime}-\theta^{\prime}$ plane. By substituting $x=r \cos \theta$ and $y=r \sin \theta$ into $r^{\prime 2}=x^{\prime 2}+y^{2}=x^{2} / \cos ^{2} \alpha+y^{2}$ gives

$r^{\prime 2}=r^{2}\left(\cos ^{2} \theta / \cos ^{2} \alpha+\sin ^{2} \theta\right)$

which after rearranging terms can be expressed as

$r^{\prime 2}=r^{2} \frac{1 / \cos ^{2} \alpha+\tan ^{2} \theta}{1+\tan ^{2} \theta}$

Using the definitions of $\theta$ and $\theta^{\prime}$, it is known that $\tan \theta=\tan \theta^{\prime} / \cos \alpha$. Substituting this relationship into Eq. (A2) yields

$r^{\prime 2}=r^{2} \frac{1+\tan ^{2} \theta^{\prime}}{\cos ^{2} \alpha+\tan ^{2} \theta^{\prime}}$ 
Multiplying $\cos ^{2} \theta^{\prime}$ to both sides of Eq. (A3) and rearranging terms results in the desired relationship

$$
r^{\prime 2}=\frac{r^{2}}{\lambda^{2}\left(\theta^{\prime}\right)}
$$

Where $\lambda\left(\theta^{\prime}\right)=\sqrt{\cos ^{2} \theta^{\prime} \cos ^{2} \alpha+\sin ^{2} \theta^{\prime}}$ is as shown earlier in the text.

Now the relationship for $d \theta / d \theta^{\prime}$ is derived by taking the first derivative with respect to $\theta$ (or $\theta^{\prime}$ for the same result) of both sides of $\tan \theta=\tan \theta^{\prime} / \cos \alpha$. This calculation yields

$$
\frac{d \theta}{d \theta^{\prime}}=\frac{1+\tan ^{2} \theta^{\prime}}{\cos \alpha\left(1+\tan ^{2} \theta\right)}
$$

Substituting $\tan \theta=\tan \theta^{\prime} / \cos \alpha$ in Eq. (A5) and rearrang- ing terms results in

$$
\frac{d \theta}{d \theta^{\prime}}=\frac{1+\tan ^{2} \theta^{\prime}}{\cos \alpha+\tan ^{2} \theta^{\prime} / \cos \alpha}=\frac{\cos \alpha}{\lambda^{2}\left(\theta^{\prime}\right)}
$$

With Eqs. (A4) and (A6) the integral of Eq. (9b) in terms of $\theta^{\prime}$ is changed to

$$
\begin{aligned}
& \left.\int_{0}^{2 \pi} \frac{\partial P}{\partial r}\right|_{r=r_{w}} d \theta \\
& =\left.\cos \alpha \int_{0}^{2 \pi} \frac{1}{\lambda^{2}\left(\theta^{\prime}\right)}\left(\frac{\partial P}{\partial r^{\prime}} \frac{\partial r^{\prime}}{\partial r}\right)\right|_{r^{\prime}=r_{w} / \lambda\left(\theta^{\prime}\right)} d \theta^{\prime} \\
& =\left.\cos \alpha \int_{0}^{2 \pi} \frac{1}{\lambda^{3}\left(\theta^{\prime}\right)} \frac{\partial P}{\partial r^{\prime}}\right|_{r^{\prime}=r_{w} / \lambda\left(\theta^{\prime}\right)} d \theta^{\prime}
\end{aligned}
$$

\begin{tabular}{|c|c|c|}
\hline$b$ & thickness of fracture zone & {$[\mathrm{L}]$} \\
\hline$g$ & gravitational constant & {$\left[\mathrm{L} / \mathrm{T}^{2}\right]$} \\
\hline$H(t)$ & test response & {$[\mathrm{L}]$} \\
\hline$H_{0}$ & initial head of the slug test & {$[\mathrm{L}]$} \\
\hline$h(x, y, t)$ & $=P(x, y, t)+x \tan \alpha$, piezometric head response in the fracture & {$[\mathrm{L}]$} \\
\hline$h_{w}(t)$ & the averaged head around the wellbore & {$[\mathrm{L}]$} \\
\hline$K$ & hydraulic conductivity & {$[\mathrm{L} / \mathrm{T}]$} \\
\hline$K_{0}(x)$ & modified Bessel function of the second kind of order 0 & \\
\hline$K_{1}(x)$ & modified Bessel function of the second kind of order 1 & \\
\hline$l$ & distance along the direction paralleling to the sloping bed & {$[\mathrm{L}]$} \\
\hline$L_{e}$ & effective water length of the slug test & {$[\mathrm{L}]$} \\
\hline$P(x, y, t)$ & pressure head response in the fracture & {$[\mathrm{L}]$} \\
\hline$q_{1}(t)$ & Darcy flow rate per unit fracture zone width along the $l$-direction & {$\left[\mathrm{L}^{2} / \mathrm{T}\right]$} \\
\hline$q_{y}(t)$ & the Darcy flow rate per unit fracture zone width along the $y$-direction & {$\left[\mathrm{L}^{2} / \mathrm{T}\right]$} \\
\hline$q^{*}(\tau)$ & dimensionless wellbore flow rate & {$[-]$} \\
\hline$r$ & distance from the test well & {$[\mathrm{L}]$} \\
\hline$r_{c}$ & radius of the riser pipe & {$[\mathrm{L}]$} \\
\hline$r_{w}$ & radius of the borehole & {$[\mathrm{L}]$} \\
\hline$r^{\prime}\left(\theta^{\prime}\right)$ & $r^{\prime}=r / \lambda\left(\theta^{\prime}\right)$ & {$[\mathrm{L}]$} \\
\hline$S$ & storage coefficient & {$[-]$} \\
\hline$s$ & Laplace transform parameter of $\tau$ & {$[-]$} \\
\hline$T$ & transmissivity & {$\left[\mathrm{L}^{2} / \mathrm{T}\right]$} \\
\hline$t$ & test time & {$[\mathrm{T}]$} \\
\hline$w(\tau)$ & $=H(t) / H_{0}$, dimensionless test response & {$[-]$} \\
\hline$x$ & $=l \cos \alpha$, the horizontal projection of $l$ & {$[\mathrm{~L}]$} \\
\hline$x^{\prime}$ & $=x / \cos \alpha$ & {$[\mathrm{L}]$} \\
\hline$Z(x, y)$ & elevation head in the fracture zone & {$[\mathrm{L}]$} \\
\hline$\alpha$ & dipping angle & {$[-]$} \\
\hline$\alpha^{*}$ & the upper limit below which the dipping angle effect can be neglected & {$[-]$} \\
\hline
\end{tabular}

Appendix B. 
Appendix B. (Continued)

\begin{tabular}{|c|c|c|}
\hline$\beta$ & damping coefficient of oscillation & {$\left[\mathrm{T}^{-1}\right]$} \\
\hline$\beta^{*}$ & $=\beta r_{c}^{2} / 2 T$, dimensionless $\beta$ & {$[-]$} \\
\hline$\eta_{P}\left(\rho^{\prime}, \tau\right)$ & $=P\left(r^{\prime}, t\right) / H_{0}$, dimensionless pressure head within aquifer & {$[-]$} \\
\hline$\eta_{w}(\tau)$ & $=h_{w}(t) / H_{0}$, dimensionless $h_{w}(t)$ & {$[-]$} \\
\hline$\theta$ & $=\tan ^{-1}(y / x)$ & {$[-]$} \\
\hline$\theta^{\prime}$ & $=\tan ^{-1}\left(y / x^{\prime}\right)$ & {$[-]$} \\
\hline$\lambda\left(\theta^{\prime}\right)$ & $=\sqrt{\cos ^{2} \theta^{\prime} \cos ^{2} \alpha+\sin ^{2} \theta^{\prime}}$ & {$[-]$} \\
\hline$v$ & $=S / T$ & {$\left[\mathrm{~T} / \mathrm{L}^{2}\right]$} \\
\hline$\rho^{\prime}$ & $=r^{\prime} / r_{w}$, dimensionless $r^{\prime}$ & {$[-]$} \\
\hline$\sigma$ & $=2 r_{w}^{2} S / r_{c}^{2}$, dimensionless storage coefficient & {$[-]$} \\
\hline$\tau$ & $=2 T t / r_{c}^{2}$, dimensionless time & {$[-]$} \\
\hline$\varphi$ & $=2 T \sqrt{L_{e} / g} / r_{c}^{2}$, dimensionless transmissivity & {$[-]$} \\
\hline$\omega$ & frequency of oscillation & {$\left[\mathrm{T}^{-1}\right]$} \\
\hline$\omega^{*}$ & $=\omega r_{c}^{2} / 2 T$, dimensionless $\omega$ & {$[-]$} \\
\hline
\end{tabular}

